\title{
Role of alumina in flexure of glass/epoxy composites
}

\author{
K PADMANABHAN and KISHORE* \\ Department of Metallurgy, Indian Institute of Science, Bangalore 560012, India \\ MS received 23 March 1990; revised 25 May 1990
}

\begin{abstract}
The influence of particulate additions of alumina on the flexural properties of glass-fabric/epoxy composites was studied. The additions improved translaminar flexural strength, while decreasing interlaminar strength. The translaminar bending modulus showed an increasing trend whereas its interlaminar value showed a decrease, up to additions of $3 \mathrm{vol} \%$. The mechanisms of deformation and the fracture features have been discussed with the aid of scanning electron microscopy.
\end{abstract}

Keywords. Alumina; filler; flexure; glass-fabric/epoxy composites; fractography.

\section{Introduction}

In fibre-reinforced epoxy composites, modification of the fibre or the matrix is effected to enhance the mechanical properties. Although, fibre hybridisation can be carried out with greater success, the addition of inorganic filler materials in the matrix is a more economic proposition. Inorganic second phase dispersions are incorporated in epoxy resin systems to enhance certain mechanical properties. Particulate fillers generally decrease the flexural strength and increase the flexural modulus of epoxy resin systems (Lee and Neville 1967). However, very few data are available on the role of particle additions in the flexural properties of fibre reinforced epoxy systems. Previous investigations report the effect of alumina trihydrate additions on the tensile strength, elastic modulus and fracture energy (Lange and Radford 1971; Radford 1971).

In this investigation, the flexural properties of a glass-fabric-reinforced epoxy composite were studied with variation in the volume fraction of alumina powders included as the particle dispersoids. It may be worthwhile to note here that no coupling agents were used in the dispersion and the particles were of about 10 microns.

Interlaminar and translaminar flexure tests were conducted at the same load to support span ratio and at three different crosshead velocities to determine the effect of alumina on the maximum fibre stress (MFS), modulus of elasticity in bending $\left(E_{B}\right)$ and the strain at failure. The results so obtained are reported here. The flexural properties of kevlar/epoxy composites at three different cross head velocities were studied earlier and the results are reported elsewhere (Padmanabhan and Kishore 1990). The effect of shear strain rates on the mechanical properties of adhesives and adhesive-joints has been reported earlier (Amijima and Fuji 1977). The present investigation includes fractography of the failed samples done mainly to correlate the mechanical test data with the fracture features.

*For correspondence. 
Table 1. Volume fraction estimation.

\begin{tabular}{lcc}
\hline Specimen type & $\begin{array}{c}\text { Fibre volume } \\
(\%)\end{array}$ & $\begin{array}{c}\text { Alumina volume } \\
(\%)\end{array}$ \\
\hline $\begin{array}{l}\text { Unfilled } \\
\text { Glass/epoxy }\end{array}$ & 57.5 & - \\
Filled & & \\
Glass/epoxy & 58.8 & $2 \cdot 10$ \\
& 58.0 & 2.96 \\
& 57.6 & 4.87 \\
\hline
\end{tabular}

\section{Experimental procedure}

The reinforcing material used was an $E$-glass fabric of seven mils, plain-weave, having a density of $2.54 \mathrm{~g} / \mathrm{cm}^{3}$ with an epoxy compatible finish. The epoxy resin used was Araldite LY 556 from Hindustan Ciba-Geigy Limited. For high temperature curing HY972 hardener was used. The alumina powders were homogeneously mixed with the resin before curing into laminates.

A hand lay-up was initially done which was then compressed in a hydraulic press and cured at $120^{\circ} \mathrm{C}$ in an oven. Thus the unfilled laminates and laminates, containing 2,3 and $5 \mathrm{vol} \%$ of alumina, and of $5 \mathrm{~mm}$ thickness, were fabricated.

To assess the volume fraction of the actual alumina particles incorporated in the samples accurate weighings were made, first for the laminates as such and then for the burnt out samples (to remove the resin), and finally for the glass fabric containing no alumina (the particles being removed by agitation). Volume fraction estimations were carried out from the three weighings, and are reported in table 1.

For the interlaminar flexure tests, the specimens used had dimensions of $100 \times 10 \times$ $5 \mathrm{~mm}$ (ASTM D790M 1984). The translaminar specimens were of the dimensions $100 \times 5 \times 5 \mathrm{~mm}$. In the latter set of samples the breadth and the depth were kept equal in order to prevent buckling during bending (Davidovitz et al 1984).

The tests were carried out in an Instron 8032 machine, at a support span to depth ratio of 16 to 1 . Three different crosshead velocities of $0.0035,0.035$ and $0.35 \mathrm{~mm} / \mathrm{s}$ were used to study the effect of strain rate on flexural properties.

\section{Results and discussion}

The MFS values of the composite plotted against the volume percent of alumina show a decreasing trend for the interlaminar and an increasing trend in the translaminar testing conditions with increasing alumina content (figure 1). Further, the failure strain of the composites, was observed to be marginally higher in translaminar tests irrespective of the alumina content (figure 2). It was also noted that the loading rate sensitivity of the alumina containing specimens was higher than those containing no alumina, under both the testing conditions (figures 3 and 4). Further, in the translaminar specimens, the MFS of the composite for different strain rates shows that strain rate sensitivity as well as the strength of the alumina containing specimens are higher than the samples containing no alumina (figure 4). Here too, specimens 


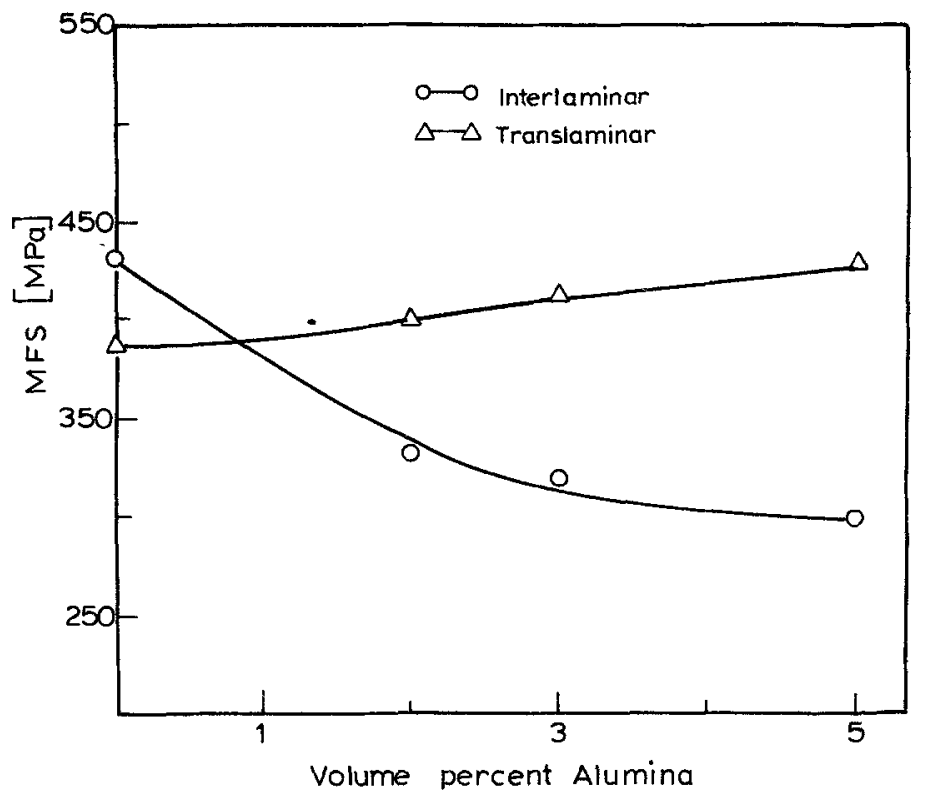

Figure 1. Maximum fibre stress vs volume percent of alumina for interlaminar and translaminar tests (loading rate $=0.035 \mathrm{~mm} / \mathrm{s}$ ).

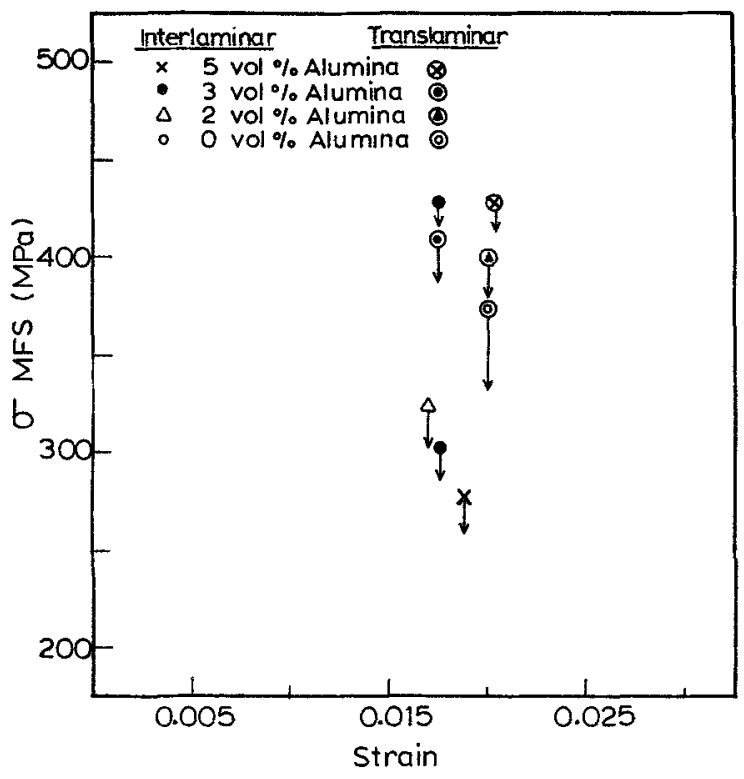

Figure 2. Maximum fibre stress and strain at failure for interlaminar and translaminar specimens (loading rate $=0.035 \mathrm{~mm} / \mathrm{sec}$ ). 


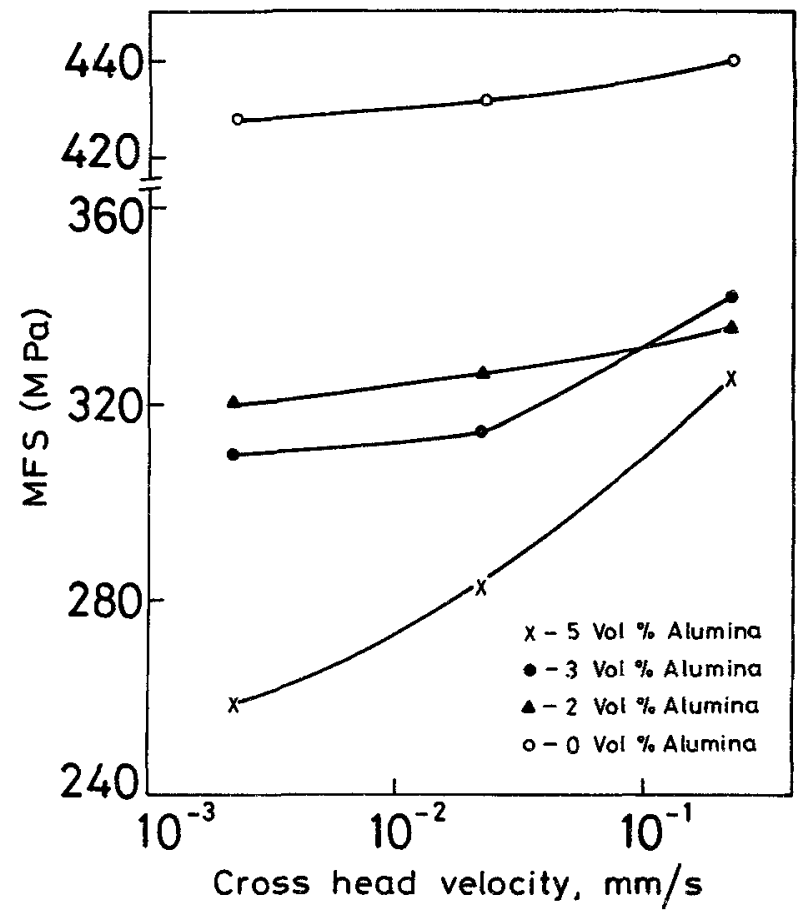

Figure 3. Variation of maximum fibre stress of interlaminar samples with crosshead velocity.

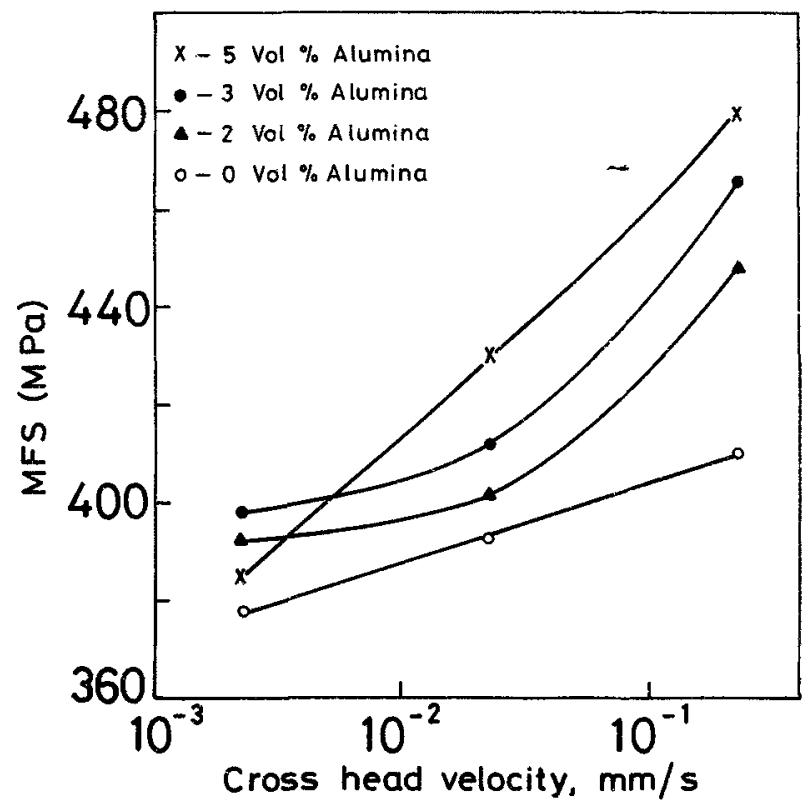

Figure 4. Variation of maximum fibre stress of translaminar samples with crosshead velocity. 


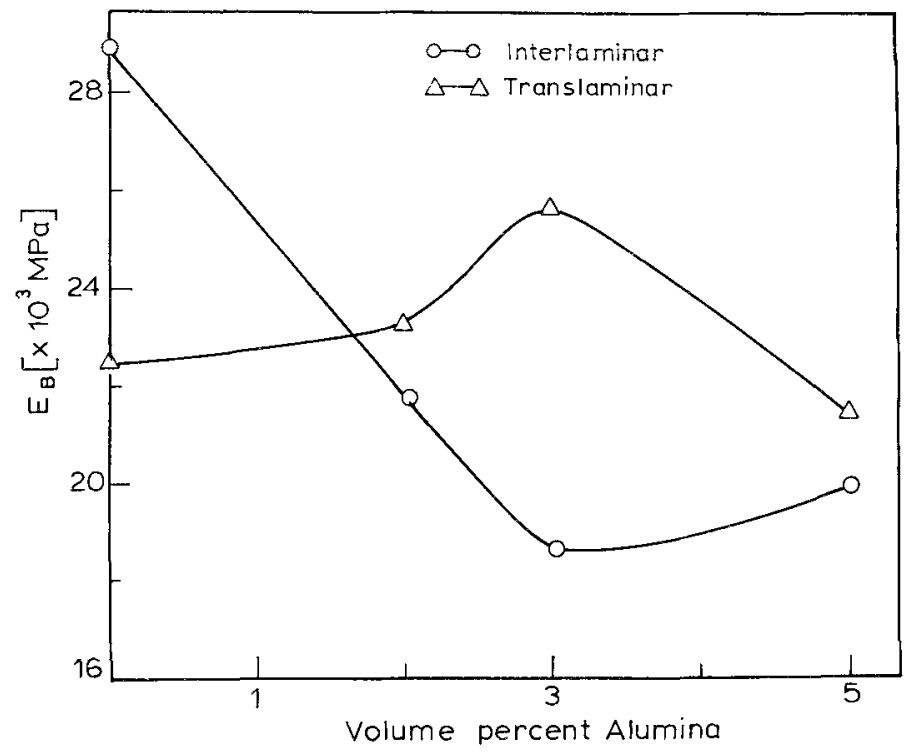

Figure 5. Modulus of elasticity in bending vs volume percent of alumina in interlaminar and translaminar specimens (loading rate $=0.035 \mathrm{~mm} / \mathrm{s}$ ).

containing $5 \mathrm{vol} \%$ of alumina show the maximum strength and strain rate sensitivity at the crosshead velocities of 0.035 and $0.35 \mathrm{~mm} / \mathrm{s}$.

The $E_{B}$ values show a decrease up to $3 \mathrm{vol} \%$ and then a marginal increase in interlaminar specimens, whereas an increasing trend was noticed in translaminar specimens up to $3 \mathrm{vol} \%$ (figure 5). The interlaminar $E_{B}$ values of the specimens containing no particles were much higher than their translaminar values. The stress concentration effects around the hard alumina particles due to the difference in their modulii as compared to that of the epoxy matrix could be one possible reason why the $E_{B}$ values show variation with respect to the alumina content. The interlaminar shear favoured by the alumina particles can be invoked to explain the decreasing $E_{B}$ values with increasing alumina content. However, it is not clear why the trend changes with further increase of alumina.

Fractography was done to study the interaction between the crackfront and the second phase particles following the work of Lange and Radford (1971). The fracture features of modified interlaminar specimens show clear splitting of the fibre due to microbuckling along the neutral axis of the individual fibres (figure 6). The microbuckling of the fibres was predominantly seen near the compression face of the sample. It was observed that the alumina particles favoured the interlaminar delamination (figure 7), which resulted in the lowered IFS values for aluminacontaining laminates. Figure 8 describes the classical features typical of a bowing-out phenomenon. Obviously the white band formation in the form of a halo depicts the stressed regions. The fractograph also illustrates the difficulty in propagation of the crack when the direction is unfavourable. Also, significant resin flow was observed in translaminar specimens as is evident from the drawing out of the matrix along the fibre directions (figure 9). Figure 10 illustrates the resin flow followed by considerable matrix cracking in a region of low stress concentration. 


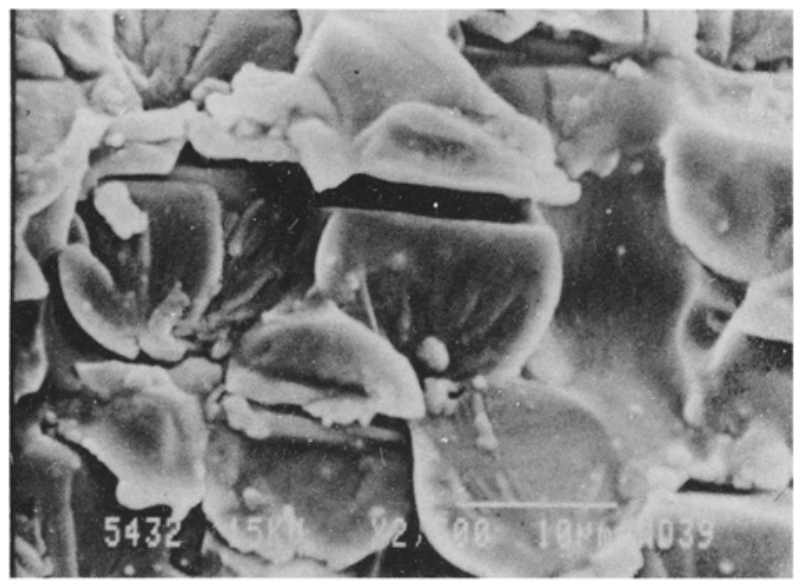

Figure 6. A typical fibre failure due to microbuckling.

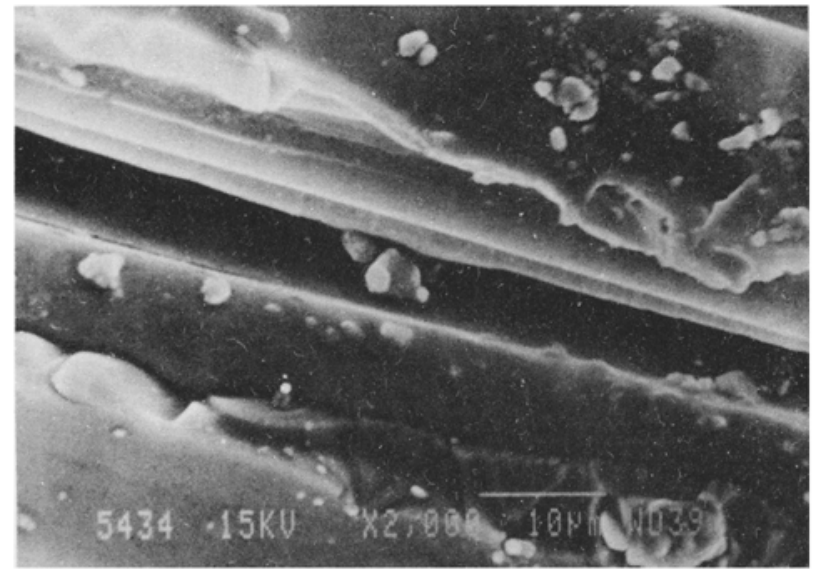

Figure 7. Alumina particles at an interlaminar delamination.

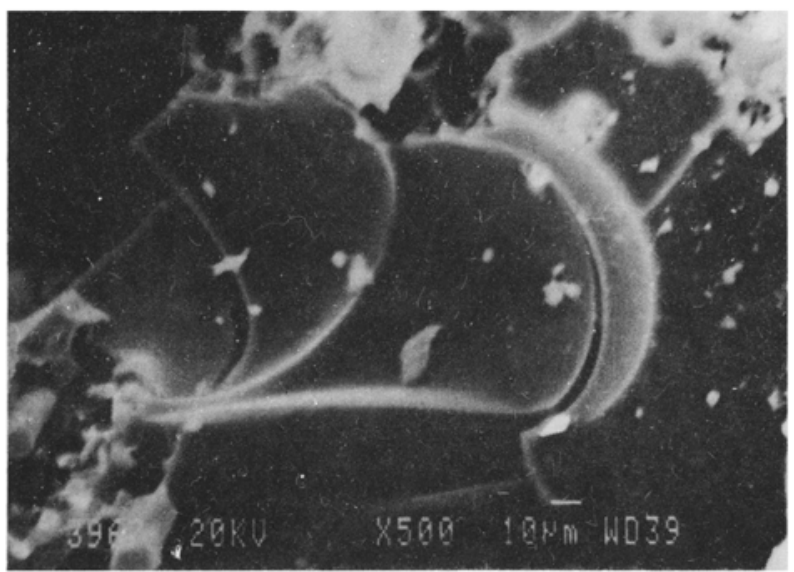

Figure 8. A crack front bowing-out in a region of inhomogeneity in translaminar testing condition. 


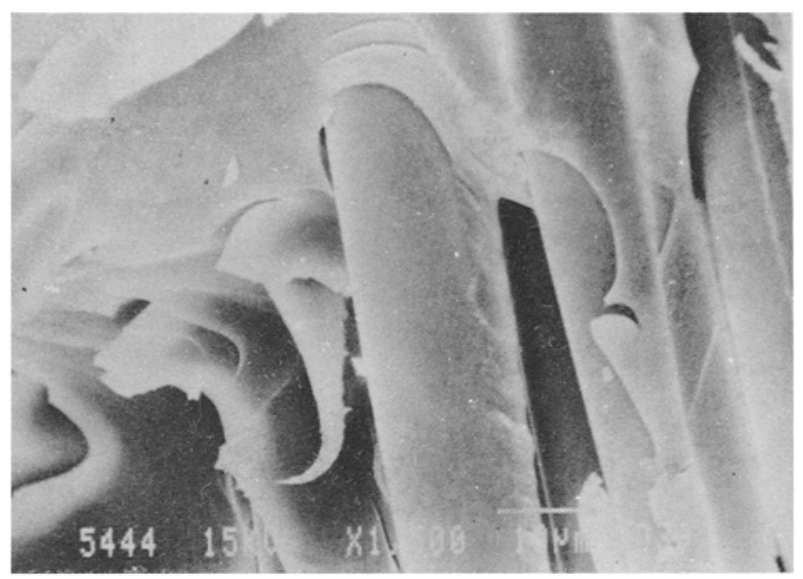

Figure 9. Matrix drawing out along the fibres in translaminar specimens.

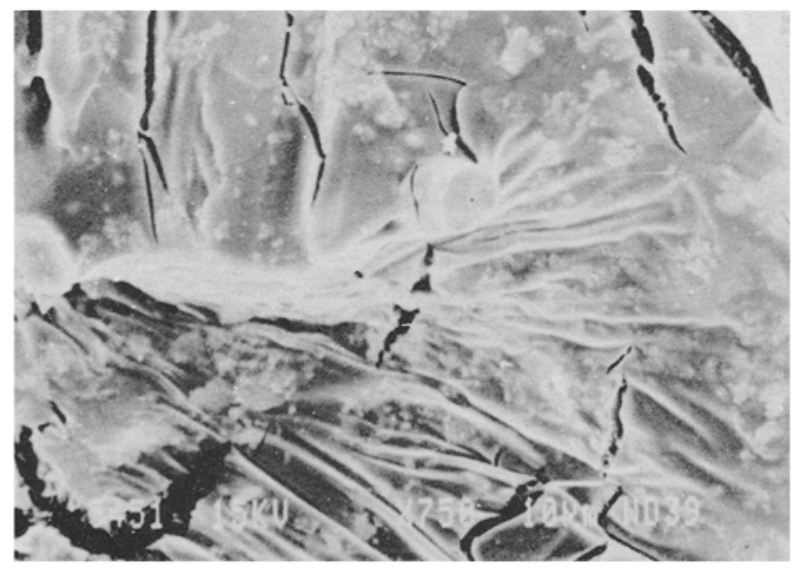

Figure 10. Resin flow followed by matrix cracking in a region of low stress concentration.

The role of alumina in the translaminar specimens can be clearly understood from figures 11 and 12. Figure 11 shows a crack front deviating due to the presence of an alumina particle near a fibre surface and terminating because of the unfavourable growth direction. That alumina can directly assist in crack tip blunting is clearly illustrated in figure 12. The crackfront during fracture is pinned at positions of inhomogeneity within the brittle matrix. This results in the bowing-out of the crackfront between the pinning positions. During propagation the crack thus forms steps (Lange and Radford 1971) in the matrix due to the bowing-out (figure 13).

In interlaminar specimens, the interply shear effects favoured by the presence of alumina explain the decrease in MFS and $E_{B}$ values. In translaminar specimens, the cracks initiated in the midspan could either be blunted at the fibre surfaces or they could undergo pinning. As the number of alumina particles increase in the matrix more crack 'pinning' and detour can be expected to occur, thereby increasing the resistance to failure and fracture energy. At higher strain rates the crackfront 


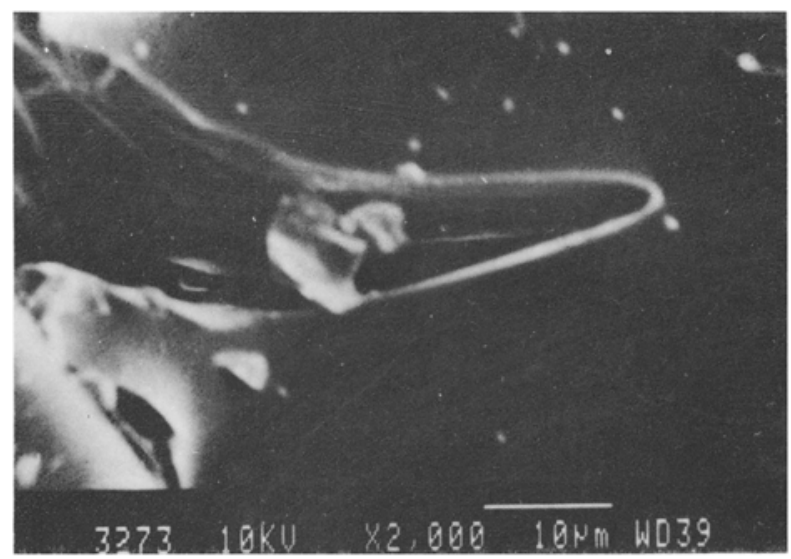

Figure 11. Crack front deviation due to alumina particle.

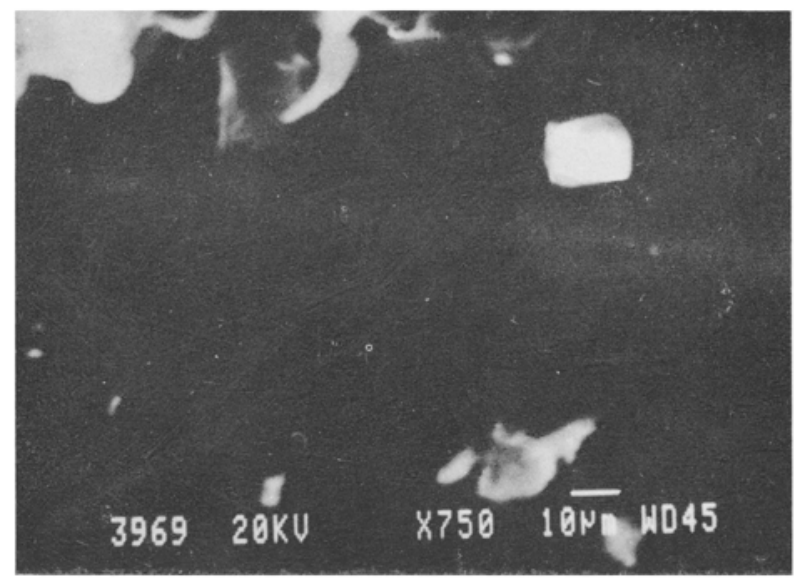

Figure 12. Crack blunting due to an alumina particle.

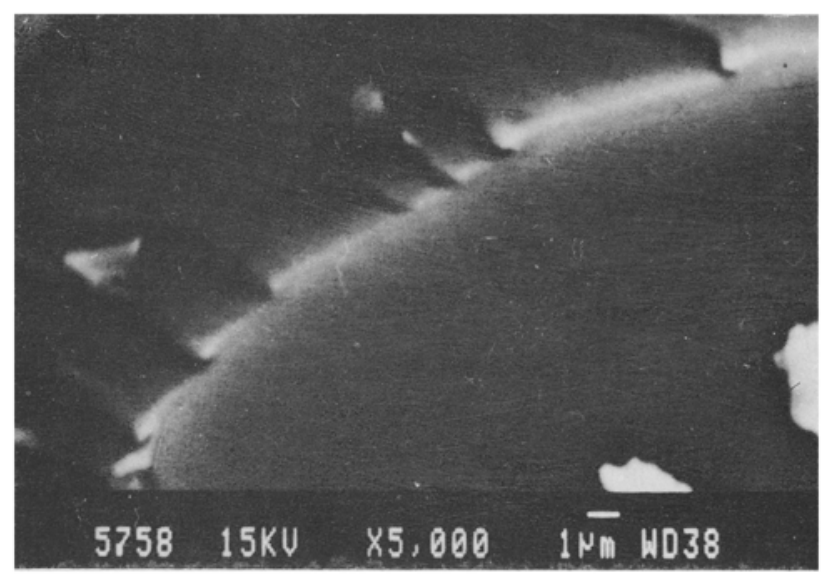

Figure 13. Step formation in the matrix due to bowing out of the crack front. 
propagation is continuous (Molony et al 1987) and encounters a greater number of obstacles leading to an increased degree of pinning and bowing-out phenomena. The translaminar specimens show modification in the MFS values with alumina additions, due to the combined effect of pinning and blunting of the crack front at higher strain rates for the abovesaid reasons.

\section{Conclusions}

(i) Particulate additions of alumina to glass/epoxy composites in the range of 2 to $5 \mathrm{vol} \%$ increase the translaminar and decrease the interlaminar flexural strength values. Further the failure strains of the translaminar specimens are slightly higher. (ii) The loading rate sensitivity of the laminates containing alumina as a second phase dispersion is found to be higher than the ones containing no alumina in interlaminar as well as translaminar tests.

(iii) The modulus of elasticity in bending initially shows a decreasing trend in interlaminar specimens and an increasing trend in translaminar specimens with increasing alumina content, up to $3 \mathrm{vol} \%$.

(iv) Fractographic features like crack-tip 'pinning' or blunting, crack front bowingout and step formation at regions of inhomogeneity are observed.

\section{Acknowledgements}

The authors express their sincere thanks to Mr Vijay Balakrishna and Mr S Sasidhara for their support during the various stages of this investigation. They also thank Prof $\mathrm{K} \mathrm{T}$ Jacob for encouragement.

\section{References}

Amijima S and Fuji T 1977 Proceedings of International Conference on Fracture Mechanics and Technology (Hong Kong: Sijthoff and Noordhoff International Publishers) vol. 1, p. 306

ASTM D790M 1984 Annual book of ASTM Standards

Davidovitz M, Mittelman A, Roman I and Marom G 1984 J. Mater. Sci. 19377

Lange F F and Radford K C 1971 J. Mater. Sci. 61197

Lee H and Neville K 1967 Handbook of epoxy resins (New York: McGraw Hill) pp. 14-17

Molony A C, Kausch H H, Kaiser T and Beer H R 1987 J. Mater. Sci. 19377

Padmanabhan K and Kishore 1990 J. Mater. Sci. Lett. 91109

Radford K C 1971 J. Mater. Sci. 61286 